Chapter 2

\title{
Culture at the Country Level
}

Robbert Maseland ${ }^{\mathrm{a}} \&$ André van Hoorn ${ }^{\mathrm{b}}$

${ }^{a}$ University of Groningen, Faculty of Economics \& Business, PO Box 800, 9700 AV, Groningen, The Netherlands. Tel: +31 503633 458, Fax: +31 503632 341, E-mail:

R.K.J.Maseland@rug.nl.

${ }^{b}$ Radboud University, Institute for Management Research, PO Box 9108, 6500 HK, Nijmegen, The Netherlands. Tel: +31 243611 663, Fax: +31 243612 379, E-mail: A.van.Hoorn@fm.ru.nl.

Draft chapter for: Van Herk, Hester, and Carlos J. Torelli, Eds. Cross-Cultural Issues in Consumer Science and International Business. Springer. 


\section{Abstract}

This chapter introduces and critically discusses the idea of measuring the culture of countries and cross-national differences therein. We start by elaborating the theoretical foundations for studying culture at the country level. We highlight the use of countries or nations as a unit of analysis and pay special attention to the way in which a group-level construct such as culture has implications at lower levels of analysis, affecting the values and beliefs of individuals. After briefly tracing the history of national culture studies, we then offer a short description of the current leading frameworks of national culture such as those by Hofstede, GLOBE and Schwartz. Throughout the chapter, the emphasis is on debates concerning extant frameworks conceptualizing and quantifying cultural differences between countries in different dimensions, which feeds into open questions concerning culture at the country level. We end with some concluding remarks.

Keywords: National culture, cultural values, cultural dimensions, Hofstede, Schwartz, GLOBE, intra-country variation, nation 


\subsection{Introduction}

This chapter introduces some of the major frameworks that have been developed to conceptualize and quantify differences in culture between countries as well as key debates surrounding these measurement exercises. In reviews of culture research, it is common to lament the many different definitions of culture that are available in the literature. In contrast, we find that several useful definitions of culture exist, all of which can serve as a basis from which to start measuring the culture of countries and cross-national differences therein. While the topic of this chapter is culture at the country level, we want to do more than merely survey the literature on this topic. Specifically, we not only seek to acquaint readers with the major national culture frameworks as they are used in the literature but also with some of the most fundamental debates concerning measures of (national) culture and their use in research. If this chapter lives up to its intentions, it should provide readers with a critical and inquisitive mindset rather than ready-made answers concerning culture at the country level.

\subsection{Culture at the Country Level}

We understand culture at the country level or national culture to be about norms, beliefs, and values that distinguish one national community from another and are transmitted from one generation to the next more or less unchanged (cf. Hofstede, 2001). A nation is a collective of individuals sharing certain relatively stable characteristics such as a language, history, traditions and habits. Nations are usually linked to a territory to which they have perceived historical ties. These commonalities are what bind people in a national community and give rise to a shared national identity. Thus, the French nation refers to the group of people that share a distinguishable set of beliefs, values, symbols and traditions that collectively characterize them as French (and 
identifies them as distinct from Germans, Italians, et cetera).

When a state legitimizes its political claim over a territory and a people through adopting a national identity, we call such a state a nation state. In the political narrative of such a state, its borders ideally overlap with the borders of the national community and the territory it claims. One of the core assumptions of national culture research is the acceptance of the claim that states represent national culture so that studying the people living within a state's boundaries means studying a single, coherent culture. The French national culture then amounts to the norms, values and beliefs of the people living in France. We discuss the validity of the assumption that countries represent cultures later on in Section 2.4.2.

Importantly, national culture is a property of groups of individuals. Hence, just like, for instance, social inequality, culture is a characteristic that is tied strictly to a specific group comprising multiple individuals and does not exist at the individual level (Welzel \& Inglehart, 2016). Nevertheless, studying national cultures requires that we start with the observation of individual behavior, values and beliefs, through survey instruments, behavioral experiments or otherwise. ${ }^{1}$ Measures of national culture are derived from these individual-level observations through some form of aggregation. In turn, researchers are usually interested in national culture because it affects the behavior of (groups of) individuals. For these reasons, any framework for studying culture also implies an underlying theory about the bidirectional relationship between

${ }^{1}$ Cross-country surveys are the most popular instruments for measuring national culture by far (Taras et al., 2009). In addition to experiments (e.g., Herrmann et al., 2008), people have also used systematic analysis of published texts to derive and quantify differences in national culture (see, for example, McClelland, 1961, Michel et al., 2011, and Skrebyte et al., 2016). 
individual values and beliefs and collective, cultural values and beliefs.

Such a theory can take different forms, ranging from undersocialized to oversocialized perspectives (Granovetter, 1985). At the undersocialized extreme, culture is simply individually determined values and beliefs aggregated at the national level. In this perspective, national culture is essentially a level of analysis, but does not itself have any separate conceptual meaning. The relevant concept revolves around the values that individuals have, which can be measured at various levels of aggregation of which the nation is one. Other levels of aggregation or units of analysis are widely considered in the literature, however, including gender, social class, birth cohort, occupation, religious denomination, et cetera (Hitlin \& Piliavin, 2004; van Hoorn, 2015b; van Hoorn \& Maseland, 2013; Kohn, 1969; Schwartz \& Rubel, 2005). At the oversocialized extreme, culture is a historically given context that autonomously determines what individuals believe, strive for, or value. In this view, culture is not only inescapable as one of the main factors influencing individuals' behavior and dispositions but also largely immutable, comparable to countries’ weather or geography (Hofstede et al., 2010).

Most approaches take a position in between these two extremes. A particularly fruitful balance between the oversocialized and undersocialized extremes is to view culture as an emergent property at the level of society, resulting from the interaction of individuals with each other and their environment. In this view, culture is not just the aggregate of the personal values of individuals but also the product of the interplay between individuals acting on their values. This emergent property in turn influences the beliefs, values and behavior of these individuals so that people within a national community develop shared norms, values and beliefs.

<Insert Figure 2.1 about here> 
This general idea can be captured in the broad model that we use as the theoretical backdrop for this chapter (Figure 2.1). This theoretical model describes the bidirectional relations between culture and individuals' values: culture emerges from the interaction between individuals acting on the basis of their values, while culture, in turn, feeds back into the values of these same individuals (Schwartz, 2014). In this model, individual-level values are only partially determined by the societal-level construct known as national culture and also the product of personal characteristics such as gender, age, education and, not least, personality. Moreover, societal-level influences extend beyond culture (or informal institutions) to include the formal institutional environment (North, 1990; Williamson, 2000).

\subsection{Frameworks of National Culture}

\subsubsection{Historical background of national culture studies}

The idea that countries possess collective traits that differentiate them from others emerged most prominently in $18^{\text {th }}$ century Europe. It was strongly linked to the formation of modern states at the time, which required the breakdown of local, traditional institutions. In this process, control over a territory came to be increasingly exercised through statewide, institutionalized laws and governing organizations. This had the effect of tying the people living in a state's territory more and more together. The manifestation of national laws and governing principles presented a strong unifying and homogenizing force over a state's subjects. Increasing interaction between citizens from different intra-national regions, spurred by the state's internal institutional harmonization, intensified this process.

While the development of state institutions homogenized populations within the state's 
borders, it also served to highlight the differences between national populations. Observers became increasingly aware of the unique ways in which different societies developed. Montesquieu (1949) attributed these differences to the interplay of national laws, government maxims, mores, customs, and natural circumstances, creating a distinct esprit general in each society. In Germany, Herder (1968) went a step further, arguing that different national characters were not the outcome of societal development, but provided the underlying cause of different development paths in the first place. In this view, nations were intrinsically distinct from each other by language, inclinations, and character. National development had to be understood as the actualization of these innate qualities (Herder, 1968; Roscher, 1918).

On the one hand, this notion of a singular national character was descriptive — it presented the societal product of modern state-building, homogenizing experiences, codifying languages, laws and regulations, and concentrating interactions within state borders. On the other hand, the concept of national character was decidedly prescriptive. Reference to a supposed underlying national spirit legitimized the increasing control of the centralized state over its citizens' lives and helped to consolidate its power. Rousseau (1964) argued that common norms, values and habits helped create a sense of collective national identity, which protected territorial integrity and acted as a safeguard against foreign domination. For this reason, societies needed to have a national character; where it did not exist, states needed to develop one (Rousseau, 1964, p. 913). Likewise, Herder (1969, p. 324) denounced multinational states, labelling these "but patched-up contraptions, fragile machines, appropriately called state-machines, for they are wholly devoid of inner life, and their component parts are connected through mechanical contrivances instead of bonds of sentiment.” In other words, state borders needed to coincide with national borders. The concept of national character was thus an intrinsic part of the propagation of the modern nation 
state, both inspiring and resulting from unification policies of new states (Beugelsdijk \& Maseland, 2011; Neiburg, 2001).

In the early $20^{\text {th }}$ century, the idea that national peoples had distinct characters culminated in the emergence of a new science of cross-cultural psychology, starting with Wilhelm Wundt's 10-volume book series on Völkerpsychologie. The specific aim of this series was to identify the common psychological essence that bound a people together and set it apart from the rest of the world (Beugelsdijk \& Maseland, 2011; Wolf, 1999). National character became a popular subject in the U.S. in the 1930s and 1940s, where it was linked to the Culture and Personality school in anthropology (Neiburg, 2011). Not unlike Wundt’s Völkerpsychologie, the Culture and Personality school assumed strong links between types of culture and types of personality, allowing researchers to apply psychological profiling to entire cultures. Its popularity in the 1940s was partly inspired by a need to develop a deeper understanding of the psyche of enemy nations. Benedict's (1946) (in)famous “The Chrysanthemum and the Sword," for example, attempted to provide an insight on the personality of the Japanese. It was commissioned by the U.S. Office of War Information to help war efforts.

This strong link to wartime policies contributed to the loss of popularity of national character studies after WWII. After two devastating world wars, fueled by nationalist myths, the idea that beliefs, values and personality types could be attributed to entire nations had become highly suspect. The breakdown of colonial empires and the coming to terms with the colonial past added to this critique. The post-colonial perspective criticized the notion that the "Other"whether it referred to the Japanese or to colonial subjects—could be entirely described in terms of a collective, static culture. Such a perspective denied colonial subjects a voice and an individual rationality of their own (Said, 1978). In this context, the idea that nationality and character were 
associated became highly controversial and was criticized for being simplistic and essentialist (Beugelsdijk \& Maseland, 2011).

After the 1950s, studies of national character were rare. The most notable exception was McClelland's The Achieving Society (1961), in which the author related differences in economic development to differences in achievement orientation in country's cultures. Measures of achievement orientation were derived from a content analysis of children's books from 41 societies, capturing to what extent these stories taught the value of working hard for an objective. Being primarily motivated by a desire to explain differences in economic performance, McClelland (1961) focused on achievement motivation as a variable highly informative of growth differences, not necessarily as a variable capturing a very relevant aspect of cultural differences as a whole. For this reason, the work only provided limited insight on differences in national culture. Interest in national culture and, particularly, its quantification rekindled with the publication of Hofstede's (1980) Culture's Consequences. In this seminal work, Hofstede exploited questionnaire data on the attitudes and beliefs of middle managers worldwide employed by U.S. multinational IBM. The main innovation in the book was the insight that variation in average scores on individual survey items between countries moved together in systematic ways. This observation allowed Hofstede (1980) to use factor analysis and identify several culture dimensions on which all societies could be scored. The idea of looking at cultural differences through the lens of universal, empirically identifiable dimensions of national culture provided a way to quantify cultural differences. This approach set off an explosion of literature linking numerical measures of cultural differences to all kinds of outcomes and phenomena (Hofstede, 2001). While most of this literature used the indicators developed by Hofstede (1980), his basic approach to measuring cultural differences has also been followed by others, most notably 
Schwartz (1994) and the Global Leadership and Organizational Behavior Effectiveness Research or GLOBE project (House et al., 2004).

Finally, there is an important subfield in the national culture literature that deserves explicit mentioning, although we do not elaborate on it in this chapter. This literature has considered socalled cultural distance between countries as a factor affecting cross-border cooperation and exchange (Kogut \& Singh, 1988; see also van Hoorn \& Maseland, 2014 and Shenkar, 2001). In this literature, country scores from culture frameworks such as those by Hofstede (1980) or GLOBE (House et al., 2004) are used to quantify cultural (dis)similarities between country dyads. Two countries are deemed more culturally close when the absolute differences between their scores on dimensions of national culture are smaller. The underlying idea is that the stronger the differences in scores on the culture dimensions between countries, the more difficult it is to organize exchange between actors from these countries (Ghemawat, 2001; Shenkar, 2001).

\subsubsection{Leading frameworks of national culture}

Table 2.1 summarizes some of the leading frameworks of national culture. As most readers are probably already familiar with these frameworks and their specific dimensions, we do not dwell on the most prominent features of these frameworks. Instead, we use this opportunity to emphasize lesser-known features of these frameworks as well as provide some background. Readers that want to know more are strongly encouraged to check the original sources.

$<$ Insert Table 2.1 about here $>$

Hofstede's (1980) framework is undoubtedly the most widely used national culture 
framework. As indicated, Hofstede applied factor analysis to data from an attitudinal survey held among employees of U.S. multinational IBM in the late 1960s and early 1970s. Originally, this factor analysis uncovered three dimensions. However, for conceptual reasons, Hofstede split one dimension into two separate dimensions for four dimensions in total. Motivated by the concern that Hofstede's (1980) four dimensions themselves might be culture-bound, a replication exercise spanning non-Western countries, particularly China, rendered evidence of a fifth dimension, independent of-and therefore adding to-Hofstede's original dimensions (The Chinese Culture Connection, 1987). The researchers that uncovered this dimension called it Confucian work dynamism, while Hofstede added it to his framework and labeled it long-term orientation (Hofstede, 1991). A sixth dimension, Indulgence vs. constraint, was added to his framework after Minkov (2007) conducted a factor analysis of data from the World Values Survey and uncovered a factor that did not correlate strongly with any of the other Hofstede dimensions (Hofstede et al., 2010).

Similar in spirit to Hofstede's framework is the framework developed by the GLOBE project (House et al., 2004). This framework identifies several dimensions of culture also identified by Hofstede but added a few novel dimensions for nine dimensions in total. A second novelty is that the GLOBE researchers considered two types of measures of national culture, namely cultural values and cultural practices. Practices thereby refer to society "as is,” while values refer to society as "should be."

Clearly distinct from Hofstede’s framework, though following the same generic approach, are the frameworks by Shalom Schwartz (e.g., 1994, 1999, 2006) and Ronald Inglehart (e.g., 1997), the latter later refined by Inglehart and Welzel (2005). Inglehart started out studying value change in Western societies, particularly the effect of affluence on the extent to which people 
emphasize non-materialist goals such as autonomy and self-expression over materialist goals such as economic security (e.g., Inglehart, 1977). He is director of the World Values Survey, which is a research network that since its inception has collected data on people's values, beliefs and attitudes in more than 100 countries worldwide. As an extension of his work on materialist/postmaterialist values, Inglehart developed a framework of cultural differences along two dimensions, each with two extremes: Traditional vs. secular/rational values and Survival vs. self-expression values.

In similar fashion, Schwartz started out studying universals in people’s basic values (see, also, Chapter 3 in this volume). He developed a framework of personal values with two outstanding features. First, values do not have absolute but only relative priorities, meaning that values can be important or unimportant only when compared to other values. Second, values have strong structural interrelationships, depending on whether they emphasize goals that are compatible or opposing. Applying some of his insights concerning personal values at the level of collectives, Schwartz developed a framework of cultural values that emphasized both the structural interrelations of cultural value orientations and the deep roots of these values in the way societies have solved fundamental dilemmas in the regulation of human behavior (see Section 2.4.1 for more details).

Overall, researchers that seek to consider national culture in their work have an array of frameworks at their disposal. We encourage readers to draw on or combine those frameworks that appear most relevant for their subject of study. Meanwhile, some frameworks, though not among the most popular, may have certain advantages, for instance, data availability or stronger conceptual foundations that would make them very attractive to use (see Table 2.1). At the least, we recommend not relying on popularity alone but consider all the obvious and not so obvious 
advantages and disadvantages of available frameworks.

\subsection{Conceptual and Operational Foundations of the National Culture Frameworks}

In many ways, Hofstede (1980) provided a blueprint for studies of national culture. Although alternative frameworks have been developed since, all these frameworks share a set of fundamental characteristics. Conceptually, all leading frameworks analyze culture in terms of culture dimensions and focus on differences in national culture. Operationally, they all rely on the aggregation of individual-level survey data to capture cross-national differences on these dimensions. We discuss these shared conceptual and operational foundations of national culture frameworks one by one.

\subsubsection{Shared conceptual foundation: A dimensional framework of culture}

All leading national culture frameworks analyze cultural differences in terms of dimensions. Countries are scored on these dimensions, allowing researchers to make meaningful comparisons between them. The method for obtaining such comparable measures of national culture involves two steps. The first step is about identifying universality in the structure of cultural values; the second step is about identifying idiosyncrasy in the importance of these values in different countries.

\section{Step 1. Identifying universality}

The starting point for national culture studies is that countries differ culturally from each other. The question to be answered is how much they differ. To answer that question, we need a measure of culture that is meaningful and relevant to all units considered, i.e., to all nations under study. 
Only when we can evaluate all cultures on a common yardstick, meaningful comparison becomes possible. Without such comparable measures, we are comparing apples and oranges.

Meanwhile, it is far from obvious that finding measures applicable to all cultures is feasible. Ethnographers have typically taken the position that since all cultures are fundamentally different, there is no set of meanings or concepts that is relevant to all of them. The patterns of behavior and meanings attached to them that have developed in a particular society only make sense within the whole of structures and meanings that is this particular society's culture (Geertz, 1973). Stated differently, if institutions and behavior can only be understood in terms of their own culture, any attempt to fit a culture in an externally imposed conceptual schema is fundamentally misguided (Geertz, 1983).

The first step towards quantifying (national) culture and cultural differences therefore is to identify and demonstrate the existence of universal dimensions on which different cultures can be scored. In other words, we need to find a common structure in the cultural differences between countries. This is usually done on a theoretical basis, statistically, or both. The most notable example of a priori theorizing is the framework developed by Shalom Schwartz (e.g., 1994, 2006). As alluded to above, Schwartz finds that all societies face the same fundamental dilemmas in regulating human activity but that the chosen solutions can vary on a range. When it comes to the relation between individuals and the collective, for instance, societies' responses can range from complete individual autonomy to being completely embedded in the group. One universal dimension of national culture in Schwartz's cultural values framework subsequently refers to the extent to which individuals are encouraged to pursue their own ideas and intellectual and positive affective experiences (Autonomy) or are members of a collective, sharing goals within a collective, exhibiting in-group solidarity and respecting traditional orders (Embeddedness). 
Hofstede (1980), in contrast, uses a statistical approach to uncover structure in cultural differences. Hofstede’s framework is founded on patterns discovered when factor analyzing the pre-existing survey data collected by IBM. Hofstede observed that when value $\mathrm{X}$ is stressed in a society usually value $\mathrm{Y}$ is stressed as well. Moreover, societies would, at the same time, disagree with values A and B. The structure apparently underlying countries' average value scores can be captured in a set of dimensions where X and Y reflect one pole and A and B the other pole. Taking this approach, Hofstede (1980) initially discovered three national culture dimensions. However, as mentioned, Hofstede had theoretical motivations to decide to break up one of these factors in two separate dimensions, specifically Individualism and Power distance.

It should be noted that the choice between a theoretical or statistical basis for the construction of culture dimensions is not absolute. Obviously, theoretically formulated dimensions are only useful when validated empirically. Likewise, the statistically derived dimensions of Hofstede (1980) should be validated by their correspondence to theoretical frameworks.

\section{Step 2. Identifying idiosyncrasy}

Step 1 provides an indispensable basis for the second step in the measurement of culture, which is to identify how countries differ on dimensions of culture thus identified. The way in which Hofstede constructed his framework, this second step would be inextricably tied to the first step. In many other cases, however, Step 2 involves some additional challenges, both conceptual ones and practical ones. Specifically, one needs to devise an appropriate measurement instrument, meaning a measurement instrument that is able to capture the identified dimensions in a reliable and valid way. Typically, this empirical operationalization of dimensions would involve designing multiple questionnaire items targeting individuals from the countries involved, although there is 
nothing against using behavioral experiments or other such measurement tools. As an example, Schwartz developed his own 57-item values survey, known as the Schwartz Values Survey or SVS, also making several refinements along the way. When it comes to measuring national culture, most attention has been paid to Step 2 and the intricacies of extracting group-level constructs from individual-level (survey) data. Similarly, the most widely discussed limitations of the national culture literature concern the identification of idiosyncrasy, for example, the (face) validity of the measurement instruments used. Notwithstanding, some of the most contentious and difficult parts of measuring national culture and differences therein involve Step 1 more so than Step 2.

Fundamentally, the issue is that in Step 2 we are focusing on the amount of differences between countries on the dimensions in the framework. However, these are just the differences in degree of what is actually homogeneous between societies. Any cultural differences that do not fit a universal structure that can be captured by cultural dimensions-differences in kind —are left out. In other words, dimensional frameworks focus exclusively on a (small) subset of cultural differences. The main challenge for any comparative national culture framework to be convincing is therefore not to show that cultures are accurately scored on the dimensions. The challenge is to identify a set of dimensions that is both valid and reflects as large a proportion of cultural differences as possible.

\subsubsection{Shared conceptual foundation: Nations as a unit of analysis}

As noted, an essential foundation for the national culture literature is the idea or assumption that culture resides at the level of the country. Strictly speaking, this idea involves two separate assumptions. First, culture is assumed to emerge around nations. Second, states or countries are assumed to represent these nations. The distinction between these two assumptions is not widely 
recognized, either by advocates or by critics of the national culture approach (Hofstede, 2001; McSweeney, 2002). Yet, they are clearly separable: the question whether the Catalan nation has a distinctive, coherent culture is independent of the question whether Catalonia is an independent state. Meanwhile, we may still question the validity of these two assumptions. As the Catalan example indicates, the above two assumptions are not obviously true. The claim that the nation is the most relevant unit along which people share cultural values is debatable, while the claim that the Spanish state or even the Catalan region represents this culture is clearly false. Yet, the general framework presented by Figure 2.1 already suggests several reasons why state borders and cultural boundaries are often likely to fall together, enough so that the national culture assumptions can be viewed to hold.

The basic reason why state borders and cultural boundaries can meaningfully coincide is that, as mentioned above, states act as homogenizing forces (Lamont \& Molnár, 2002; Martindale, 1967). They do so in three main ways. First, states are an important source of the external environment with which individuals interact (Figure 2.1). States set laws, create and maintain institutional arrangements, and develop policies. States further make political decisions—going to war, printing money - that have consequences for the nation's population as a whole. Finally, states may actively promote certain shared values and ideas among its population or exercise control over the information individuals can access. In doing all the above, states create shared experiences among their citizens. These shared experiences, in turn, are reflected in a degree of sharedness of values that emerges at the level of the country.

Second, states create and support the formal institutions that are necessary for effective and meaningful interaction. Without a well-developed institutional framework, cooperation suffers from prohibitive transaction costs. Without clear contracting laws and an accessible judicial system 
supporting them, it is difficult to trust one another enough to enter into an exchange (North, 1990). Without a shared (official) language, it is difficult to communicate. Because the laws and institutions created by states set the stage for interactions, such interactions end up being relatively concentrated within the jurisdictions of states. Intra-country trade volumes, for example, dwarf inter-country trade volumes (e.g., McCallum, 1995). In terms of Figure 2.1, the concentration of interactions within state borders implies that the culture emerging out of these interactions is also likely to be limited to these state borders. Hence, when states create the conditions for interaction and exchange, they also create the platform on the basis of which shared cultural values, norms and beliefs can emerge.

Third, states typically promote the construction of a national identity following territorial borders. Doing so, they foster the emergence of the nation as an imagined community (Anderson, 1991). Nations are typically far too large for all members to interact with each other, certainly not on a regular basis. That implies that nations are not actual communities in the sense of groups of people cooperating and interacting frequently. However, citizens often consider themselves part of a distinctive community of people represented by the nation, as nationality is a chief criterion for social categorization including self-identification (Barth, 1969; Lamont \& Molnár, 2002; Smith, 1991). This sense of belonging to a national community creates imagined shared experiences, in addition to the actual shared experiences discussed before. Observing what happens to fellow nationals will be interpreted as part of one's own experience as a member of the nation. What is more, in addition to the fact that states create the institutional conditions for actual interaction and exchange between its citizens, national communities also stimulate a sense of imagined interactions: fellow nationals perceive each other as people they to some extent know and are familiar with, even when they have never met before. Importantly, this reference to an 
imagined joint national identity in turn facilitates actual interaction between fellow nationals and creates hurdles for interaction with other nationalities. In this way, an imagined national community further fosters the emergence of culture at the national level. In practice, nationality is associated with a range of stereotypes or prejudices (Katz \& Braly, 1933; Madon et al., 2001), which in turn can be traced back to specific features of a nation such as its economic success (Lee \& Fiske, 2006). More generally, people use nation or nationality heuristically, as a signal that allows them to make inferences about unobservable traits of individuals or products on the basis of their membership association with a particular nation (see, van Hoorn, 2016 for a recent application to migrant workers; Chapter 7 discusses the literature on so-called country-of-origin effects in (product) evaluations). Overall, nation turns out to be a very natural way for people to draw group boundaries and to consider differences between groups thus identified. The imagination of a national community thus acts as a powerful catalyst for the homogenization of national culture, even without actual interactions and shared experiences.

To be complete, states have not only worked to homogenize culture within their borders; the borders of states are also historically partially determined by national-cultural boundaries (e.g., Desmet et al., 2011). The ideology of the nationalism emerging in the late $18^{\text {th }}$ century legitimized control of states over a certain territory and people by reference to a shared, common culture and identity. While thus strengthening existing national states, this close ideological link between nation and state eroded the legitimacy of multinational empires, such as the Austro-Hungarian Empire and the Ottoman Empire. It also provided a motivation/justification for the unification of countries such as Germany and Italy. Nationalism thus encouraged the redrawing of the European political map along national-cultural lines. Outside Europe, nationalism played a similarly important role in the breakdown of colonial empires. 
For these reasons, while nation, culture and state are by no means necessarily linked, in practice they are typically associated closely enough to warrant the use of states as units of national culture (Smith, 2004). Indeed, some researchers find nation to be the principal vessel of culture (Wallerstein, 1991). However, it is important to be aware that this close association is a historically contingent one and that it does not necessarily hold for all countries at all points in time. The assumption that states represent distinct national cultures may be justified for $20^{\text {th }}$ century Europe, but for young states with externally imposed borders such as in Sub-Saharan Africa this assumption is likely more problematic.

\subsubsection{Shared operational foundation: Reliance on aggregated individual-level survey data}

If we have decided that we want to measure cultural differences of degree between countries, how can we go about doing so? There are a number of operational characteristics shared by all leading frameworks of national cultural differences. In order to quantify differences in values, all of them make use of data from cross-country surveys designed to elicit respondents' values. A battery of questionnaire items - the measurement instrument-is included in surveys in a large set of countries, enabling systematic comparison of individuals' responses. In order to say something about cultural differences, all frameworks subsequently engage in some form of aggregation of the individual-level survey data to the societal level. These operational features of national culture frameworks bring about important challenges that have been addressed differently in different frameworks.

\section{Instrument and questionnaire design}

The first challenge is about what questionnaire items to include in one's survey. Culture is about 
norms, beliefs and values. Leading national culture frameworks typically focus on studying cultural values, however, even when in practice it is not always clear whether particular questionnaire items for measuring cultural differences truly refer to values only and not to other mental constructs (cf. Table 2.1). ${ }^{2}$

When designing (or selecting) questionnaire items that national culture researchers believe are capturing important aspects of values, these researchers almost inevitably reason from their own cultural perspective. Such culture-boundedness implies that important values are likely to be missed and/or that the measurement instrument may include survey items that are deemed irrelevant by some of the groups of respondents considered. A way to address this is by working with multicultural research teams when designing the measurement instrument and specific questionnaire items. Incorporating perspectives from different cultures would help ensure that proposed survey items have similar relevance in all settings under investigation. Schwartz (1994) and GLOBE (House et al., 2004) have explicitly done so. The IBM survey exploited by Hofstede (1980), in contrast, was not initially designed to capture differences in cultural values and while multicultural teams were involved, these teams were not systematically used to address potential biases due to culture-boundedness. Hence, the items in the IBM survey were not checked beforehand for their cross-national relevance for capturing value differences. ${ }^{3}$

\footnotetext{
${ }^{2}$ Values can be defined as non-situation-specific guidelines that provide the basis for evaluation and direct people in selecting between alternative courses of action (Schwartz, 1992, p. 5).

${ }^{3}$ As alluded to above, in later work, Hofstede implicitly acknowledges this concern with his original work and the likely cultural bias present in his framework. Specifically, Hofstede (1991)
} 


\section{Language and cross-cultural translation of survey items}

When a suitable measurement instrument has been designed, a second operational challenge concerns language, specifically the translation of the selected questionnaire items. In order to facilitate cross-cultural comparison, researchers need to make sure that selected value items carry the same meaning in different populations. Importantly, in culture research, such translation goes beyond finding the correct word. Some words simply do not have a direct equivalent in another language and have to be described through circumlocution (Hofstede, 2001). In addition, even when words can be translated, they may have different connotations in different cultural contexts. Words may be much more common in the original language than in their translation, for example, so that the latter may bring connotations with highly educated discourse. Moreover, even when the right words have been found, interview and response styles are likely to differ between cultures (Harzing, 2006; see also Chapter 10 in this volume). All these issues require making use of highquality translators. A common way of checking the validity of translations is by making use of back-translation: after translation of an item, another translator translates the item back into the original language, after which the resulting text is compared to the original. This approach is followed by Schwartz (1994) and GLOBE (House et al., 2004), among others, but not by Hofstede (1980).

\section{Sampling and representativeness}

includes a fifth dimension, long-term orientation, which was identified by The Chinese Culture Connection (1987). 
When selection and translation of items has been concluded, the next challenge is to select respondents. If the objective is to provide a representative picture of cultural differences, there are several approaches possible. One option is to target a group of respondents for each country that is maximally representative of these countries' cultures. Afterwards, weights may be used to control for under-represented and over-represented groups in the raw data. This is the strategy in the World Values Survey (Inglehart, 1997). An alternative strategy is the one advocated by Hofstede (1980): taking a matched sample of respondents that is as homogenous as possible except for nationality. The IBM survey would meet this criterion. The disadvantage of the latter approach is that the resulting data are not representative of countries' populations as a whole. When the research objective is not to accurately describe individual cultures but to identify cultural differences instead, representativeness could be less of a problem than it may seem at first sight, however. Specifically, Hofstede (2001) finds that by surveying the same small, functionally equivalent segment of the population in all countries one controls for all kinds of omitted variables.

Notwithstanding, the validity of the matched sampling strategy is conditional on the assumption that national culture has a uniform effect on values across all sub-populations of a country. The corollary of this assumption is that the surveyed segment of the population is atypical for the population as a whole in the same way across countries (Hofstede, 2001). In Hofstede’s case, consider the (plausible) scenario in which IBM personnel around 1970 was almost exclusively male; in that case, the survey only captures differences in national cultures as long as one assumes that the differences between national male sub-cultures are identical to the differences between national female sub-cultures. Such extrapolation of male-only sample results to females has long been discredited in other disciplines (Pinn, 2005), making this a questionable assumption. 
For these reasons, other frameworks prefer a combination of matched and representative sampling or avoid claiming that their results hold beyond the specific population segment under study. Schwartz (1994) uses matched samples of schoolteachers and university students to ensure maximum comparability, combining this evidence with occupationally heterogeneous samples of adults to increase representativeness. GLOBE surveys managers only, but limits conclusions to national differences in managerial cultures (House et al., 2004). Such differences notwithstanding, the resulting measures of culture correlate strongly between the frameworks, suggesting that whichever choices one makes does not end up having much effect on measured national culture.

\subsection{Limitations and Debates in the National Culture Literature}

Since the publication of Hofstede (1980), studying national culture in terms of cultural dimensions has become the dominant approach in quantitative culture studies. The popularity of this approach notwithstanding, there are some important limitations associated with it. Some of these are simply generic limitations that are not necessarily unique to measures of national culture. In all comparative research, for example, we want to make sure that we are measuring the same thing for each of the different units of analysis considered (see above). Another such basic issue in comparative research concerns the accurate representation of populations in terms of a minimum number of observations. ${ }^{4}$ Some of the limitations are more specific to or particularly challenging

\footnotetext{
${ }^{4}$ So far, the national culture literature has not settled on a clear guideline concerning the minimum number of individual respondents that would be required to ensure that the country scores that one obtains are representative. Hofstede's work suggests that 20 respondents would be enough, although a minimum of 50 respondents would be preferred (e.g., Hofstede \& Minkov, 2013).
} 
for national culture research, however. Hence, to conclude this chapter, below, we discuss what we see as some of the most important issues and debates involving national culture.

\subsubsection{Cultural bias and ethnocentrism}

Given the premise that cultures are different and people from different cultural backgrounds are likely to have different priorities and mental models, it is more than likely that any framework designed to study cultural differences is itself embedded in the cultural background of the researcher. Although the risk of cultural bias is a feature of all universalistic models in social sciences, because of the nature of the subject this type of bias is especially salient in national culture research. We have discussed some of the specific challenges in the discussions of instrument and survey design and translation that we presented above. In general, multicultural research teams are the best safeguard against cultural bias, provided members of the team operate on an equal footing and that the multicultural team is involved in all steps of the research design. More fundamentally, however, it may be argued that cultural bias or ethnocentrism is inherent to the project of comparative cultural studies (Clifford \& Marcus, 1986; Harootunian, 2005). Radical critics argue that by imposing external categories on a culture, i.e., categories that are not derived from and do not make sense within this particular culture itself, one denies members of that culture a voice of their own. Subjects are thus reduced to a "comparative existence,” i.e., they are described

However, if we consider what researchers have done in practice, we can find that the GLOBE project has calculated scores for one of the countries in its sample using 13 respondents (House et al., 2004). In contrast, the World Values Survey and European Values Study, as used by Inglehart, have at least a couple of hundred respondents per country and many times several thousand. 
in terms of the extent to which they resemble an externally derived idea (Harootunian, 2005) and are apparently unable (or not allowed) to describe themselves in their own terms (Clifford \& Marcus, 1986). For this reason, ethnographers typically dismiss comparative cultural studies on principle.

The question here is whether cultures are unique wholes that can only be understood in their totality, rendering cultural differences absolute, or whether universal structures are underlying cultural differences between societies. In our view, some of the most important aspects of cultural differences between countries are about different axioms and mental models creating a worldview that is unique to the culture in question. Differences in specific values, however, may exhibit a universal structure, making comparative analysis possible.

\subsubsection{The validity and relevance of dimensional frameworks}

The above discussion of the foundations of national culture frameworks has already introduced some issues that speak to the validity of the various measures of national culture available in the literature. In general, the (construct) validity of national culture measures can be undermined by a range of factors. In the debate that followed the appearance of the GLOBE framework, a most prominent validity concern has become whether the leading frameworks of cultural values are in fact measuring cultural values (e.g., Taras et al., 2010). As depicted in Figure 2.1, national culture is but one of many factors affecting the personal values of individuals. Hence, a specific open question in the national culture literature is whether systematic societal variation in survey responses is of a genuinely cultural nature or perhaps driven by differences in circumstances (Maseland \& van Hoorn, 2009, 2010). Maseland and van Hoorn (2011), for example, show that cross-country differences in the valuation of democracy reflect variation in the actual level of 
democratic institutions in a country rather than underlying cultural dispositions.

An even more challenging threat to the usefulness of dimensional frameworks derives from the idea of universality, as emphasized in the first step of constructing a dimensional framework of cultural differences. It is not uncommon for proponents of the leading frameworks of national culture to tout their framework's comprehensiveness, meaning that their framework is acclaimed to capture all the relevant variation in national culture or cultural values. Hofstede (2006), for instance, presents a factor analysis of the dimensions identified by the GLOBE framework to argue that the latter framework contains some dimensions that are redundant and is not, in fact, more comprehensive than Hofstede's own framework. The more relevant question, however, concerns the extent to which a set of dimensions of national culture and the specific measurement instruments used to operationalize these dimensions are able to capture the whole of cross-country differences in national culture. To illustrate, the focus on conceptualizing and quantifying cultural values differences in the above-discussed frameworks already suggests that these frameworks miss out on differences in cultural beliefs. More importantly, however, the whole enterprise of measuring national culture is subject to what we like to refer to as "funneling effects" (Figure 2.2), even when the focus is on values only. In the end, national culture and cultural values are latent constructs and any effort to quantify them must acknowledge the possibility that we are measuring only a small portion of them.

$<$ Insert Figure 2.2 about here $>$

As highlighted by Figure 2.1, national culture is but one of many factors influencing people's values. Indeed, empirical research consistently finds that within-country variation in 
values dwarfs between-country variation in values (e.g., Fischer \& Schwartz, 2011). ${ }^{5}$ Hence, an important reason why funneling effects occur has to do with the approach of aggregating individuals' value scores, which inevitable leads to some loss of information about potentially relevant variation in values. Similarly, it is not clear whether aggregation of individual values automatically implies capturing culture as an emergent property of groups. A specific concern is that the cultural values, norms and beliefs of a group only become salient in actual interactions between the members of a particular culture (see Figure 2.1). If so, aggregations of individuals' answers on questionnaire items would contain some useful information but would probably fail to capture some of the most fundamental cultural differences between groups. Finally, there is the standard concern in comparative research concerning the nature of differences, specifically differences in degree vs. differences in kind (see above). Conceptually, completeness, meaning the absence of funneling, would require that we can, in fact, express the whole of cultural differences between countries as a matter of degree, measured on universally valid dimensions. Even in this hypothetical case, however, it is not clear that we can actually design a measurement instrument that is both universal and exhaustive, covering the whole of cultural differences between countries. Meanwhile, the claim that a particular framework provides a comprehensive account of national culture differences can only be falsified and not proven. The best one can do when proposing a

\footnotetext{
${ }^{5}$ A typical decomposition is that between 5-15\% of total values diversity is between countries and that the remaining $85-95 \%$ of total variation in values is between individuals from the same country. Note, though, that this latter number is inflated and the former number deflated, as both total variation and within-country variation comprise invalid variance that is due to measurement error (van Hoorn, 2015a).
} 
framework is to make a theoretically informed case that certain dimensions are relevant and likely to capture a substantial amount of cultural differences between countries. Future research, however, can still uncover further dimensions that would need to be added in order for the framework to be comprehensive, as is nicely illustrated by the evolution of Hofstede's framework from four to six dimensions (The Chinese Culture Connection, 1987; Hofstede, 1980; Hofstede, 1991; Hofstede et al., 2010; Minkov, 2007). In general, the essential open question in national culture research is about funneling effects and not knowing exactly how much of relevant differences in national cultural we have actually been able to quantify.

\subsubsection{Individuals and national culture as a dependent variable}

Throughout this chapter, we have emphasized the group-level nature of culture. When it comes to the use of national culture measures in research, however, typically the interest is in national culture as a predictor of phenomena that occur and exist at the level of individuals or other such actors that reside in specific nations (see, for example, Chapter 4 in this volume). Going back to Allport (1924), Robinson (1950) and Thorndike (1939), however, researchers have warned for the pitfalls of using aggregate-level relationships and constructs to make inferences about lower-level phenomena, what is known as the ecological fallacy. A generic concern is that correlations that exist at the aggregate level, i.e., between aggregate-level measures and constructs, do not exist in the same form at lower levels of analysis, i.e., between individuals. A more specific concern is that any single individual cannot be seen as representing an entire culture. At best, we may recognize that individuals are affected by aggregate-level constructs and apply a multilevel approach to keep track of and distinguish between different levels of analysis (see Chapter 11 in this volume). Even when taking a multilevel approach, however, we should be wary of assuming simple relationships 
between individual-level constructs or outcomes on the one hand and their higher-level predictors on the other. As highlighted by the various arrows in Figure 2.1, there is very little to suggest that the relationships between culture and individual-level outcomes are anything but complex.

Increasingly, culture researchers are aware of possible ecological fallacies and multilevel approaches are gaining in popularity. Still a great deal of progress can be made, for instance, when it comes to explicit modeling of the bi-directional interaction between culture and individuals' values (cf. Figure 2.1). Similarly, most work that involves some measure of cross-national differences in values continues to focus on country means and tends to neglect variation in values that occurs within nations, in turn, leading to an overemphasis of culture as a source of values differences compared to other sources of values differences (see Beugelsdijk et al., 2015a for an exception in the context of cultural distance).

\subsubsection{Cultural change and national culture in a globalizing world}

Building on the idea that national culture exists, researchers have also long wondered about whether and how cultures change (Beugelsdijk et al., 2015b). In the view of some-and Hofstede most prominently—national cultures and cultural differences are extremely stable over time (Hofstede 2001, p. 34). Other culture researchers, however, have been more appreciative of the possibility of systematic changes in the culture of countries (e.g., Inglehart \& Baker, 2000). Much of the interest in the temporal (in)stability of culture derives from the ongoing economic integration of nations, which is said to have a globally homogenizing effect (Appadurai, 2011; Ritzer, 2004). Much as states foster a process of cultural homogenization within their borders, so increasing international interconnectedness would be a transnational homogenizing influence that renders traditional interstate borders increasingly less relevant as a boundary for distinct cultures. The 
specific question asked, then, is whether cultures worldwide are changing to become more similar, what is known as cultural convergence, or whether cultures exhibit persistent differences, what is known as cultural divergence (Webber, 1969).

As it turns out, this question is rather difficult to answer, both empirically and in terms of specific trajectories of cultural change. Concerning the former, a particular challenge is to separate genuine shifts in cultural values from temporary changes due to, for instance, random fluctuations over time (van Hoorn, 2013; Twenge et al., 2010). Concerning the latter, a main challenge is that the answer to the question whether culture is converging or diverging does not have a simple yesor-no answer, as the answer may vary depending on which dimension of culture one considers. The so-called crossvergence perspective (Ralston, 2008) proposes a hybrid conceptualization of convergence in which cultures may be converging on some dimensions but remain dissimilar on other dimensions. This framework has been heavily criticized, however (e.g., Witt, 2008). A specific concern is that the concept of crossvergence is too general to have much meaning, as the prediction of convergence on some dimensions but divergence on other dimensions is essentially unfalsifiable. Overall, the question of the relevance both of cultural change and of cultural convergence/divergence as phenomena affecting national culture is still very much unanswered and one of the main empirical questions.

\subsection{Concluding remarks}

Frameworks of culture at the country level or national culture are widely used in a variety of disciplines. Although, culture is a complex concept that, many would argue, defies comprehensive definition, several scholars have sidestepped such concerns and have gone on to present measures and frameworks for quantifying national culture and differences therein. Judged by the widespread 
use of their frameworks-Hofstede, for instance, is said to be one of the most-cited social scientists - they have succeeded in doing so. At the least, the large-scale quantification of countries' culture seems to have hit a nerve among researchers with a comparative interest in countries.

In this chapter we have sought to introduce the reader to the idea that country-level culture exists and can be meaningfully measured. For sure, there are still many open questions when it comes to conceptualizing and quantifying national culture and differences therein. In fact, our aim was more to familiarize the reader with some of the core issues in the national culture literature than to give a complete and detailed description of all the different national culture frameworks that are out there. We have achieved our aim if this chapter leaves the reader with more rather than fewer questions than before.

\section{References}

Allport, F.H. (1924) 'The group fallacy in relation to social science', American Journal of Sociology, Vol. 29, p.699-706.

Anderson, Benedict. "Imagined Communities. 1983. rev. ed." (1991).

Appadurai, Arjun. "Disjuncture and difference in the global cultural economy 1990." Cultural theory: An anthology 2011 (2011): 282-295.

Baskerville, R. F. (2003). Hofstede never studied culture. Accounting, Organizations and Society, 28(1), 1-14.

Benedict, R. (1946/1967). The chrysanthemum and the sword: Patterns of Japanese culture. Houghton Mifflin Harcourt. 
Benedict, R. (1946/1967). The chrysanthemum and the sword: Patterns of Japanese culture. Houghton Mifflin Harcourt.

Beugelsdijk, S. and Maseland, R. 2011 Culture in Economics: History, Methodological Reflections and Contemporary Applications. Cambridge: Cambridge University Press.

Beugelsdijk, S., Maseland, R., Onrust, M., van Hoorn, A., and Slangen, A. (2015a), 'Cultural distance in international business and management: From mean-based to variance-based measures,’ International Journal of Human Resource Management, 26, 165-191.

Beugelsdijk, S., Maseland, R., \& Van Hoorn, A. (2015b). Are scores on Hofstede’s dimensions of national culture stable over time? A cohort analysis. Global Strategy Journal, 5(3), 223240.

Clifford, J., \& Marcus, G. E. (1986). Writing culture: the poetics and politics of ethnography: A School of American Research advanced seminar. University of California Press.

Desmet, Klaus, Michel Le Breton, Ignacio Ortuño Ortín, and Shlomo Weber (2011), ‘The Stability and Breakup of Nations: a Quantitative Analysis,' Journal of Economic Growth, 2011, $16,183-213$

Fischer, R., \& Schwartz, S. (2011). Whence Differences in Value Priorities?: Individual, Cultural, or Artifactual Sources. Journal of Cross-Cultural Psychology, 42: 1127-1144.

Geertz, C. 1973. 'Thick Description: Toward an interpretive theory of culture', in The interpretation of cultures, New York: Basic Books, pp. 3-30.

Geertz, C. 1983. Local Knowledge: further essays in interpretive anthropology. New York: Basic Books.

Granovetter, M. (1985) Economic Action and Social Structure: The Problem of Embeddedness. American Journal of Sociology, 91, 481-510. 
Harootunian, H. (2005). Some thoughts on comparability and the space-time problem. Boundary 32(2), 23-52.

Harzing, A. W. (2006). Response styles in cross-national survey research a 26-country study. International Journal of Cross Cultural Management, 6(2), 243-266.

Herder, Johan Gottfried (1968) Reflections on the Philosophy of the History of Mankind (178491) Chicago: The University of Chicago Press.

Herder, Johan Gottfried (1969) Social and Political Culture, Cambridge: Cambridge University Press.

Herrmann, Benedikt, Christian Thöni, and Simon Gächter. "Antisocial punishment across societies." Science 319.5868 (2008): 1362-1367.

Hitlin, S., \& Piliavin, J. A. (2004). Values: Reviving a dormant concept. Annual Review of Sociology, 30, 359-393.

Hofstede, G. (1980). Culture’s Consequences: International Differences in Work-Related Values. Beverly Hills, CA: Sage Publications.

Hofstede, G. (1991). Cultures and Organizations: Software of Mind. London: McGraw Hill.

Hofstede, G. (2001). Culture’s Consequences: Comparing Values, Behaviors, Institutions, and Organizations Across Nations (2nd ed.). London: Sage Publications.

Hofstede, G. (2006). What Did GLOBE really measure? Researchers' minds versus respondents' minds. Journal of International Business Studies, 37, pp. 882-896.

Hofstede, G., Hofstede, G.-J., \& Minkov, M. (2010). Cultures and organizations: Software of the mind. Third edition. New York: McGraw-Hill.

Hofstede, G., \& Minkov, M. (2013). Values Survey Module 2013 Manual. Version: August 25 2013. 
Hoorn, A. van (2013). Is a Global Business Culture Coming? A Cross-National Analysis of Generational Shifts in Managerial Values. SOM Research Report No. 13012-GEM, University of Groningen.

Hoorn, A. van (2015a). Differences in work values: Understanding the role of intra- versus intercountry variation. International Journal of Human Resource Management, 26: 1002-1020.

Hoorn, A. van (2015b). The global financial crisis and the values of professionals in finance: An empirical analysis. Journal of Business Ethics, 130(2), 253-269.

Hoorn, A. van (2016). Trust and Signals in Workplace Organization: Evidence from Job Autonomy Differentials between Immigrant Groups. SOM Research Report No. 16006GEM, University of Groningen.

Hoorn, A. van, \& Maseland, R. (2013). Does a Protestant work ethic exist? Evidence from the well-being effect of unemployment. Journal of Economic Behavior \& Organization, 91, $1-12$.

Hoorn, A. van, \& Maseland, R. (2014). Is distance the same across cultures? A measurement equivalence perspective on the cultural distance paradox, In R. Van Tulder, S. Lundan, \& A. Verbeke (Eds.), Multinational enterprises, markets and institutional diversity (Progress in International Business Research (Vol. 9)). Howard House: Emerald.

House, R. J., Hanges, P. J., Javidan, M., Dorfman, P. W., \& Gupta, V. (Eds.). (2004). Culture, Leadership, and Organizations: The GLOBE Study of 62 Societies. Thousand Oaks: Sage Publications.

Inglehart, R. (1977). The Silent Revolution: Changing Values and Political Styles among Western Publics. Princeton, NJ: Princeton University Press.

Inglehart, R. (1997). Modernization and Postmodernization: Cultural, Economic, and Political 
Change in 43 Societies. Princeton, NJ: Princeton University Press.

Inglehart, R., \& Welzel, C. (2005). Modernization, Cultural Change and Democracy: The Human Development Sequence. New York: Cambridge University Press.

Inglehart, R., and Baker, W.E. (2000), 'Modernization, Cultural Change, and the Persistence of Traditional Values', American Sociological Review, 65, 19-51.

Katz, D., \& Braly, K. 1933. Racial stereotypes of one hundred college students. Journal of Abnormal and Social Psychology, 28: 280-290.

Kogut B, Singh H. 1988. The effect of national culture on the choice of entry mode. Journal of International Business Studies 19: 413-431.

Kohn, M.L. (1969), Class and Conformity: A Study in Values, Homewood, IL: Dorsey Press.

Lamont, Michèle and Virag Molnár. 2002. “The Study of Boundaries in the Social Sciences.” Annual Review of Sociology 28:167-195.

Lee, T. L., \& Fiske, S. T. 2006. Not an outgroup, not yet an ingroup: Immigrants in the stereotype content model. International Journal of Intercultural Relations, 30: 751-768.

Madon, S., Guyll, M., Aboufadel, K., Montiel, E., Smith, A., Palumbo, P., \& Jussim, L. 2001. Ethnic and national stereotypes: The Princeton trilogy revisited and revised. Personality and Social Psychology Bulletin, 27: 996-1010.

Martindale, D. 1967., National Character in the Perspective of the Social Sciences, The Annals of the American Academy of Political and Social Science, Vol. 370 (March 1967), pp. 3035.

Maseland, R., \& van Hoorn, A. (2009). Explaining the negative correlation between values and practices: a note on the Hofstede-GLOBE debate. Journal of International Business Studies, 40(3), 527-532. 
Maseland, R., \& Van Hoorn, A. (2010). Values and marginal preferences in international business. Journal of International Business Studies, 41(8), 1325-1329.

Maseland, R., \& van Hoorn, A. (2011). Why Muslims Like Democracy Yet Have So Little of It. Public Choice, 147, 481-496

McCallum, John. "National Borders Matter: Canada-U.S. Regional Trade Patterns." American Economic Review, June 1995, 85(3), pp. 615-23.

McClelland, D.C. 1961. The achieving society. Oxford, England: Van Nostrand

McSweeney, B. (2002): Hofstede’s model of national cultural differences and their consequences: A triumph of faith - a failure of analysis. Human Relations 55(1), pp. 89-118.

Michel, J. B., Shen, Y. K., Aiden, A. P., Veres, A., Gray, M. K., Pickett, J. P., ... \& Pinker, S. (2011). Quantitative analysis of culture using millions of digitized books. Science, 331(6014), 176-182.

Minkov, M. 2007. What Makes Us Different and Similar: A New Interpretation of the World Values Survey and Other Cross-Cultural Data. Klasiki I Stil: Sofia.

Montesquieu, Baron de, 1949. The Spirit of the Laws, trans. Thomas Nugent. New York: Hafner, pp. 293-294.

Neiburg, F. 2001. National Character, in: Smelser, N. J., \& Baltes, P. B. (Eds.). International encyclopedia of the social \& behavioral sciences (Vol. 11). Amsterdam: Elsevier, Pages 10296-10299.

North, D.C. (1990), Institutions, institutional change, and economic performance, New York: Cambridge University Press.

Pinn, V. W. (2005). Research on women's health: Progress and opportunities. Journal of the American Medical Association, 294(11), 1407-1410. 
Ralston, D.A. (2008). The Crossvergence Perspective: Reflections and Projections. Journal of International Business Studies, 39: 27-40.

Ritzer G. 2004. Americanization, McDonaldization, and globalisation. In Issues in Americanization and Culture, Campbell N, Davies J, McKay G (eds). Edinburgh University Press: Edinburgh, U.K.; 41-60.

Robinson, W. S. (1950). Ecological correlations and the behavior of individuals. American Sociological Review, 15, 351-357.

Roscher, W. 1918 [1854]. Grundlagen der Nationalökonomie. Stuttgart and Berlin: Gotta’fche Buchhandlung Nachfolger.

Rousseau, Jean-Jaques 1964 Projet de constitution pour la Corse in Oeuvres complètes, ed. Robert Derathé (Bibliothèque de la Pléiade, Paris, 1964), III, 899-950; Considérations sur le gouvernement de Pologne et sa réformation projettée, Oeuvres, III, 951-1041; Emile, Oeuvres, IV, 826-833, 850-853.

Said, E. (1978) Orientalism. New York: Pantheon.

Schwartz, S. H. (1992) Universals in the Context and Structure of Values: Theoretical Advances and Empirical Tests in 20 Countries. In Zanna, M. (Ed.) Advances in Experimental Social Psychology. New York Academic.

Schwartz, S. H. (1994). Beyond individualism/collectivism: New cultural dimensions of values. In U. Kim, H. C. Triandis, C. Kagitcibasi, S. C. Choi \& G. Yoon (Eds.), Individualism and Collectivism: Theory, Methods and Applications (pp. 85-119). London: Sage.

Schwartz, S. H. (1999). A theory of cultural values and some implications for work. Applied Psychology, 48(1), 23-47.

Schwartz, S. H., \& Rubel, T. (2005). Sex differences in value priorities: Cross-cultural and 
multimethod studies. Journal of Personality and Social Psychology, 89, 1010-1028.

Schwartz, S.H. (2006). A theory of cultural value orientations: Explication and applications. Comparative Sociology, 5: 137-182.

Schwartz, Shalom H. "Rethinking the concept and measurement of societal culture in light of empirical findings." Journal of cross-cultural Psychology 45.1 (2014): 5-13.

Shenkar, O. (2001). Cultural distance revisited: towards a more rigorous conceptualization and measurements of cultural differences. Journal of International Business Studies, 32, pp. 519-535

Skrebyte, A., Garnett, P., \& Kendal, J. R. (2016). Temporal Relationships Between IndividualismCollectivism and the Economy in Soviet Russia: A Word Frequency Analysis Using the Google Ngram Corpus. Journal of Cross-Cultural Psychology, 0022022116659540.

Smith, A. D. (1991). National identity. Reno / Las Vegas: University of Nevada Press.

Smith, P. B. (2004). Nations, cultures and individuals: New perspectives and old dilemmas. Journal of Cross-Cultural Psychology, 35(1), 6-12.

Taras, V., \& Steel, P. (2009). Beyond Hofstede: Challenging the ten testaments of cross-cultural research. In C. Nakata (Ed.), Beyond Hofstede: Culture Frameworks for Global Marketing and Management. Chicago, IL: Macmillan/Palgrave.

Taras, V., Rowney, J., and Steel, P. (2009), 'Half a century of measuring culture: Approaches, challenges, limitations, and suggestions based on the analysis of 121 instruments for quantifying culture', Journal of International Management, 5, 357-373.

Taras, V., Steel, P., \& Kirkman, B. L. (2010). Negative practice-value correlations in the GLOBE data: Unexpected findings, questionnaire limitations and research directions. Journal of International Business Studies, 41(8), 1330-1338. 
The Chinese Culture Connection. (1987). Chinese values and the search for culture-free dimensions of culture. Journal of Cross-Cultural Psychology, 18, 143-164.

Thorndike, E. (1939). On the fallacy of imputing the correlations found for groups to the individuals or smaller groups composing them. American Journal of Psychology, 52, 122124.

Twenge, J.M., Campbell, S.M., Hoffman, B.R., \& Lance, C. E. (2010). Generational differences in work values: Leisure and extrinsic values increasing, social and intrinsic values decreasing. Journal of Management, 36: 1117-1142.

Wallerstein, I. M. (1991). Geopolitics and geoculture: Essays on the changing world-system. Cambridge University Press.

Webber, R.A. (1969). Convergence or divergence? Columbia Journal of World Business, 4: 7584.

Welzel, C., \& Inglehart, R. F. (2016). Misconceptions of Measurement Equivalence: Time for a Paradigm Shift. Comparative Political Studies, 49(8),

Williamson, O. (2000), 'The New Institutional Economics: Taking Stock, Looking Ahead,' Journal of Economic Literature, 38, 595-613.

Witt, M.A. (2008). Crossvergence 10 years on: Impact and further potential. Journal of International Business Studies, 39: 47-52.

Wolf, E.R. 1999. Envisioning Power: Ideologies of Dominance in Crisis. Berkeley/ Los Angeles/ London: University of California Press. 
Figure 2.1: Cultural, individual and environmental influences on personal values.

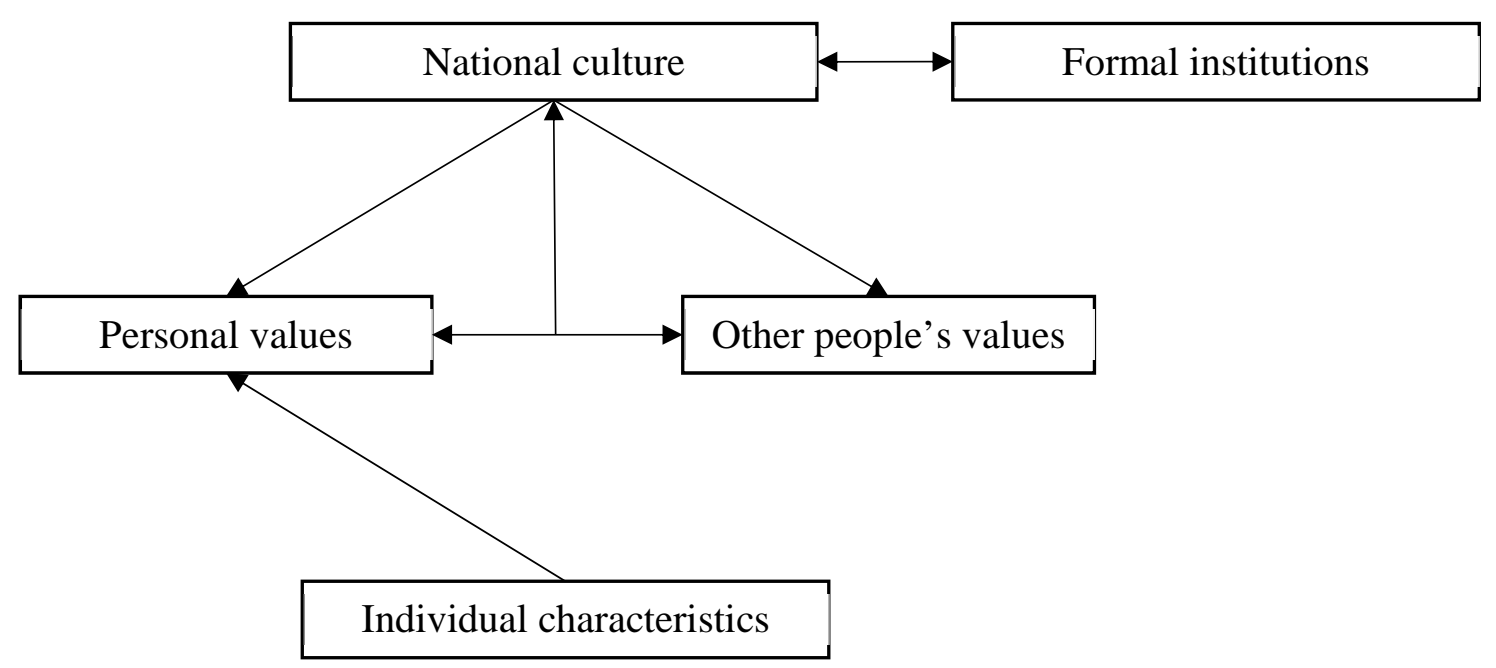

Source: Adapted from Schwartz (2014). 
Figure 2.2: Funneling effects in quantifying differences in national culture.




Table 2.1: Key features of the main frameworks of national culture.

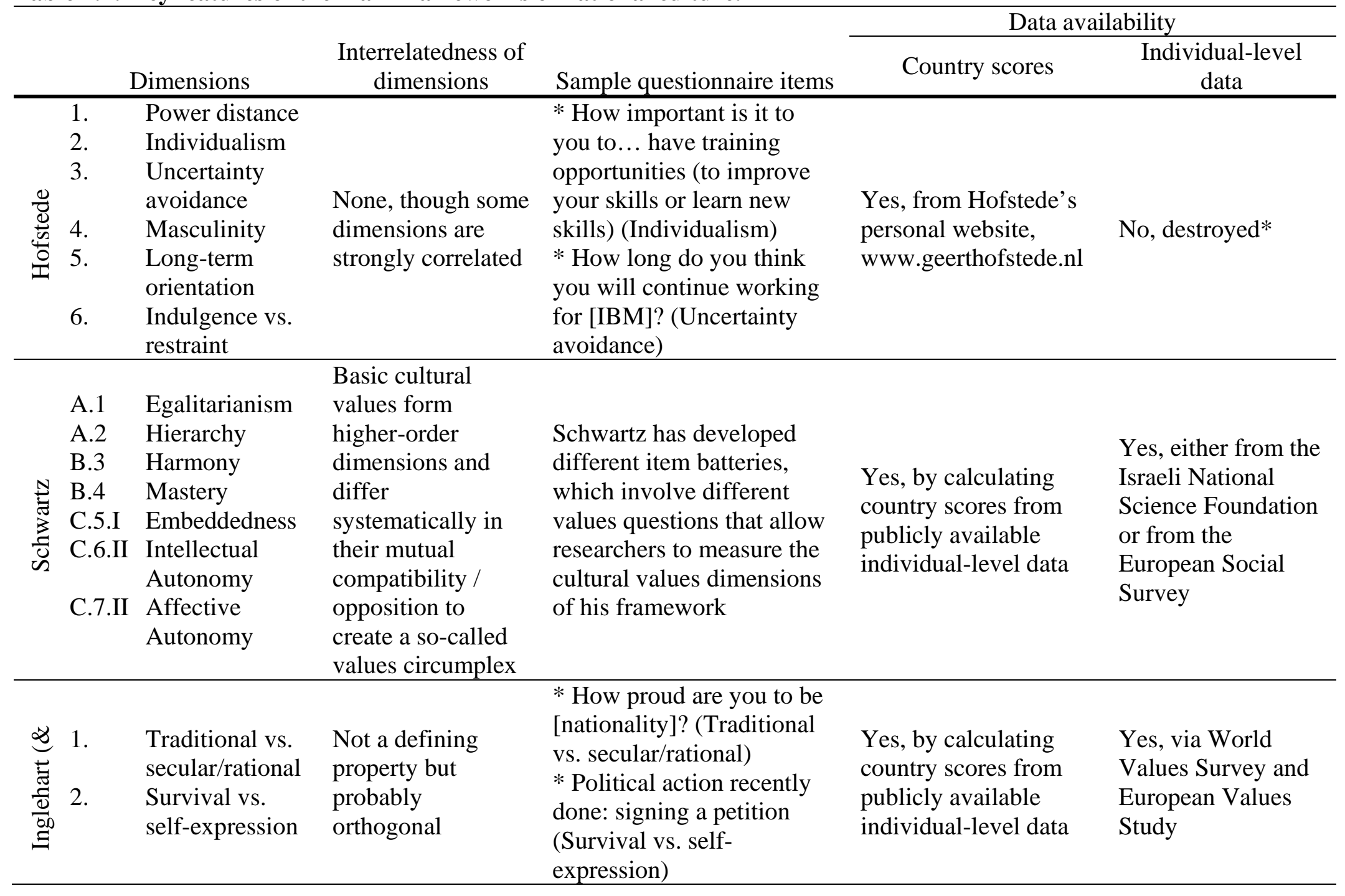


Table 2.1, ctd.



